\title{
ARGININE-VASOPRESSIN BINDING SITES IN RAT BRAIN: A QUANTITATIVE AUTORADIOGRAPHIC STUDY
}

\author{
A. BIEGON*, M. TERLOU**, Th.D. VOORHUIS and E.R. DE KLOET*** \\ Rudolf Magnus Institute for Pharmacology, Medical Faculty, University of Utrecht, Vondellaan 6, 3521 \\ GD Utrecht (The Netherlands)
}

(Received October 10th, 1983; Revised version received and accepted November 30th, 1983)

Key words: vasopressin - receptors - autoradiography - densitometry - brain

Specific binding sites for arginine-vasopressin (AVP) were detected in rat brain after incubation of tissue sections with $\left[^{3} \mathrm{H}\right] \mathrm{AVP}$. AVP and two selective AVP antagonists are capable of displacing $\left[{ }^{3} \mathrm{H}\right] \mathrm{AVP}$ with an $\mathrm{IC}_{50}$ in the $10^{-8}-10^{-7}$ molar range, while oxytocin and $\mathrm{ACTH}_{4-10}$ were much less effective. The neuroanatomical distribution of $\left[{ }^{3} \mathrm{H}\right] \mathrm{AVP}$-labeled sites was studied with autoradiography utilizing tritium-sensitive LKB film and computerized densitometry for quantitative analyses of the film images. The highest density of $\left.{ }^{3} \mathrm{H}\right] \mathrm{AVP}$ binding sites was observed in hippocampal regions, the lateral septum, olfactory and amygdaloid nuclei, and the nucleus tractus solitarii (NTS) of the brainstem.

Arginine-vasopressin (AVP) influences memory processes [4, 6]. This action of AVP takes place in certain discrete limbic-midbrain regions [7]. AVP also acts on biochemical and electrophysiological processes in these areas. It was found that the peptide affects indices for catecholamine turnover in the hippocampal dentate gyrus, dorso-lateral septum and nucleus tractus solitarii (NTS) [7, 12], and alters the firing pattern of neurons in the lateral septum [5]. Immunocytochemical studies have demonstrated that these limbic-midbrain regions are innervated by AVPcontaining neurons [3]. Recent advances in autoradiographic methods introduced by Kuhar and coworkers [8] have made it possible to study receptor distribution in vitro in brain sections. A modification using tritium-sensitive sheet film has been introduced [9]. Based on this method preliminary reports have appeared showing that autoradiography of $\left[{ }^{3} \mathrm{H}\right] \mathrm{AVP}$ binding sites is feasable $[2,10,13]$. In the present

\footnotetext{
* On leave of absence from the Department of Isotopes, Weizmann Institute of Sciences, Rehovot, 76100 Israel.

**Zoological Laboratory, Department of Light Optical Registration, University of Utrecht, Trans III, Padualaan 8, $3584 \mathrm{CH}$ Utrecht, The Netherlands.

***Author for all correspondence.
} 
study we used densitometry for quantitative evaluation for film images obtained by in vitro autoradiography of $\left[{ }^{3} \mathrm{H}\right] \mathrm{AVP}$-labeled binding sites in rat brain.

Twelve male Wistar rats of our own breeding and two male Brattleboro rats homozygous for diabetes insipidus (Central Breeding Laboratories, TNO, Zeist, The Netherlands) weighing $150-200 \mathrm{~g}$ at the time of sacrifice were used for the experiments. Light in the animal house was on from 05.00 to $19.00 \mathrm{~h}$ and the animals were sacrificed between 09.00 and $10.00 \mathrm{~h}$ by decapitation. The brains were rapidly removed from the skull and frozen in dry ice. Tissue preparation and autoradiographic procedures were performed according to previously published methodology [9]. For autoradiographic localization $32 \mu \mathrm{m}$ sections were preincubated for $20 \mathrm{~min}$ at room temperature in a $0.17 \mathrm{M}$ Tris buffer, $\mathrm{pH} 7.6$, containing $4 \mathrm{mM} \mathrm{CaCl}_{2}$. After drying, $10 \mathrm{nM}\left[{ }^{3} \mathrm{H}\right] \mathrm{AVP}(\mathrm{NEN}, 42.1 \mathrm{Ci} / \mathrm{mmol}$ ) in a total volume of $300 \mu \mathrm{l}$ buffer $\left(0.1 \mathrm{M}\right.$ Tris, $0.1 \% \mathrm{BSA}, 0.5 \mathrm{mg} / \mathrm{ml}$ bacitracin, $10 \mathrm{mM} \mathrm{MgCl}_{2}$ ) was applied to the sections and they were incubated for $30 \mathrm{~min}$ at room temperature followed by $2 \times 4 \mathrm{~min}$ washes in Tris $0.17 \mathrm{M}$ at $4^{\circ} \mathrm{C}$ and a short dip in distilled water to remove buffer salts. In adjacent sections $1 \mu \mathrm{M}$ unlabeled AVP was included to correct for non-specific binding. Slides were dried at $60^{\circ} \mathrm{C}$ and opposed to LKB ultrofilm for 1 month. Eight tissue standards containing known amounts of tritiumlabeled leucine per mg protein were exposed alongside the samples. Following standard developing and fixing procedures the autoradiograms were examined with an IBAS-2 image analysis system (Kontron, München, F.R.G.). The images of the autoradiograms of both one section and the set of tissue standards were simultaneously registered by a videocamera equipped with a Plumbicon tube. The image is digitalized and stored in one of the image memories (resolution $512 \times 512$ pixels). The areas to be measured, including the background, were delimited interactively. After subtraction of the background value, the determined optical density values were expressed as values in $\mathrm{fmol} / \mathrm{mg}$ protein by recalculation on the basis of the optical density data each time obtained from the set of tissue standards.

Optimal conditions of the binding were determined on sections which were removed for scintillation counting. The primary goal was to examine the competition of endogenous AVP for the externally applied $\left[{ }^{3} \mathrm{H}\right] \mathrm{AVP}$. Two methods were employed to circumvent this potential source of errors. Firstly, a pre-incubation of the tissue section for $20 \mathrm{~min}$ at room temperature in the presence of $\mathrm{Ca}^{2+}$ and absence of peptidase or protease inhibitors to promote release and degradation of endogenous AVP. Secondly, the use of Brattleboro rats homozygous for diabetes insipidus, who lack endogenous AVP. While pre-incubation had no effects on displaceable binding on brain sections of Brattleboro rats, which exhibited about $32 \%$ specific binding, in normal rats preincubation $(20 \mathrm{~min})$ increased specific binding from $4 \%$ to more than $30 \%$ of total binding (hippocampal coronal level). We concluded that a 20 min pre-incubation is sufficient for removal of endogenous AVP and this interval was adopted in further experiments.

For characterization of the binding site specificity related and unrelated peptides 
were tested for competition with $10 \mathrm{nM}\left[{ }^{3} \mathrm{H}\right] \mathrm{AVP}$ for its binding sites. Of the compounds tested, AVP and the AVP antagonists [1] dPTyr(Me)-AVP (AAVP ${ }^{a}$ ) and $\mathrm{d}\left(\mathrm{CH}_{2}\right)_{5} \mathrm{Tyr}(\mathrm{Me}) \mathrm{AVP}\left(\mathrm{AAVP}{ }^{\mathrm{b}}\right.$ ) exhibited $\mathrm{IC}_{50 \mathrm{~S}}$ in the $10^{-7}$ and $10^{-8}$ molar range $\mathrm{ACTH}_{4-10}$ and oxytocin were competing only in the $\mu$ molar range (cf. IC $\mathrm{IC}_{50} \mathrm{~s}$ of AVP, AAVP and AAVP': 30, 190 and $60 \mathrm{nM}$ respectively).

Fig. 1 shows examples of the localization of $\left[{ }^{3} \mathrm{H}\right]$ AVP binding sites in coronal sections of the rat brain. The concentration of binding sites in a number of regions is summarized in Table $I$. The highest density of specific binding sites was observed in the ventral hippocampus, the CA3 pyramidal cells of the hippocampus, the olfactory nucleus, lateral septum and NTS. A considerable amount of binding sites was also observed in the gyrus dentatus, hippocampal molecular layer, the CA1 and CA2 pyramidal cells, entorhinal cortex, central amygdaloid nucleus, medial geniculate nucleus, and substantia nigra. Striatal, hypothalamic, thalamic and medullary brain regions in general contained low amounts of $\left[{ }^{3} \mathrm{H}\right] \mathrm{AVP}$-labeled binding sites.

The present study shows that the rat brain contains high affinity binding sites labeled with [ $\left.{ }^{3} \mathrm{H}\right]$ AVP. The distribution of binding sites is uneven in the brain with highest density in extrahypothalamic limbic brain regions. The displacement of $\left[{ }^{3} \mathrm{H}\right]$ AVP by excess unlabeled AVP in regions rich in binding sites was $50-60 \%$, which exceeds very well the $30-40 \%$ displacement observed after scintillation counting of the labeled brain sections (this study and refs. 2 and 10). Baskin et al. [2] and Van Leeuwen and Wolters [10] found displaceable binding in the dorsal septal area. In the first report [2], however, preincubation of the brain sections was not reported. This study clearly shows that preincubation is necessary to unmask AVP binding sites. Preincubations were used in the study of Yamamura et al. [13], but occurred in the presence of bacitracin. In our study the use of bacitracin in the preincubation was avoided since it would prevent degradation of endogenous AVP. During the labeling of the binding sites with $\left[{ }^{3} \mathrm{H}\right] \mathrm{AVP}$, there was however bacitracin in the medium and HPLC analyses showed that there were no conversion products of the peptide detectable.

The highest concentrations of specific $\left[{ }^{3} \mathrm{H}\right]$ AVP binding were found in hippocampal, septal, amygdaloid and olfactory regions and the NTS. The hippocampal, septal and amygdaloid regions have been demonstrated to respond to microinfusion of AVP and related peptides as measured by indices of behavioral performance [4] and catecholamine neurotransmission [7, 12]. The NTS has a role in blood pressure regulation. Effects of AVP have been described in autonomic regulation of blood pressure [11] and the NTS is densely innervated by AVP fibers [3]. The sites tested at the coronal level of the dorsal hippocampus display high affinity to AVP and two selective AVP antagonists. $\left[{ }^{3} \mathrm{H}\right] \mathrm{AVP}$ is, however, not displaced by a 100 -fold excess of oxytocin. It is therefore tempting to speculate that the binding sites visualized, quantified and partially characterized in the present study represent an AVP receptor system. 

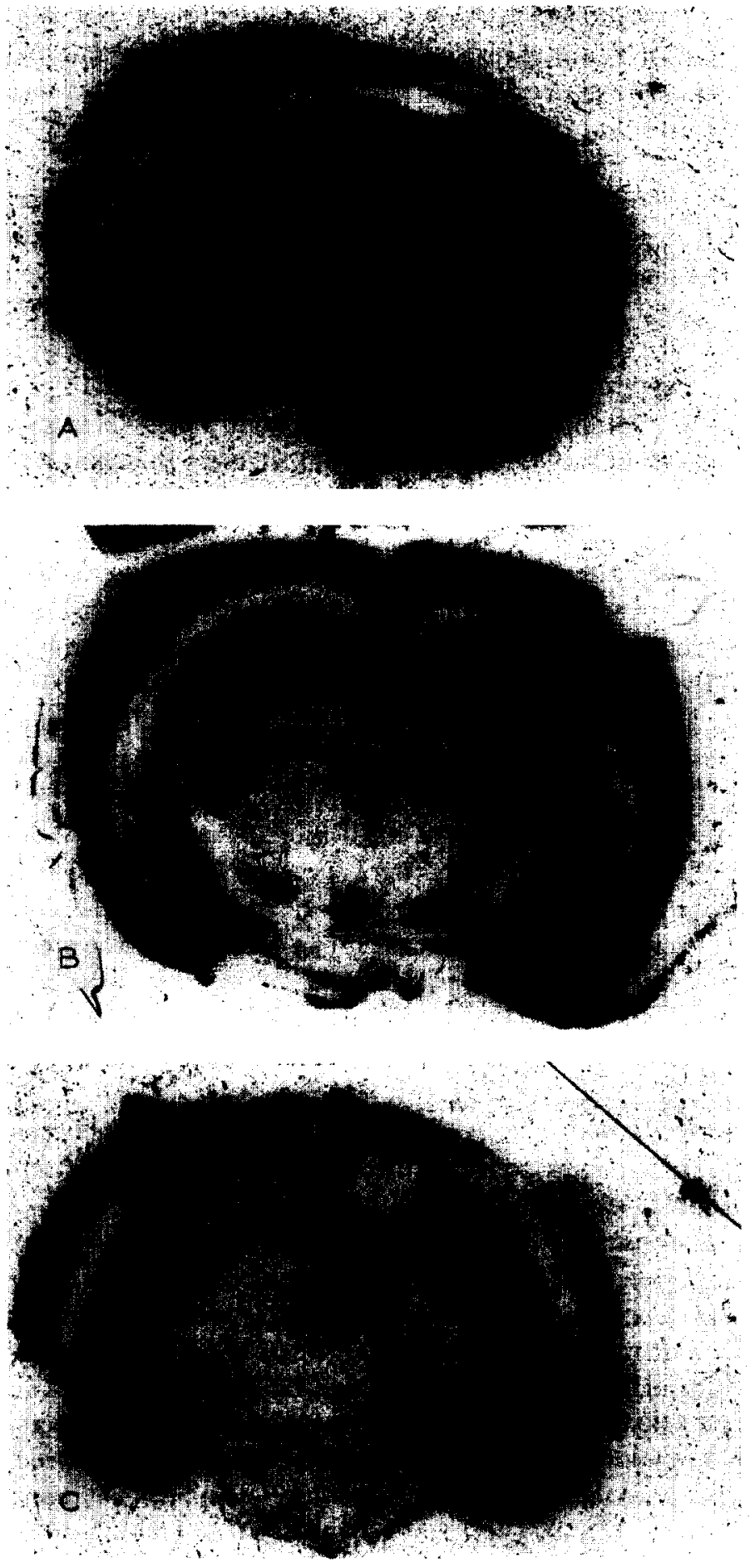
TABLE I

DENSITY (in fmol/mg protein) OF SPECIFIC BINDING SITES LABELED WITH $10 \mathrm{nM}\left[^{3} \mathrm{H}\right] \mathrm{AVP}$ IN VARIOUS BRAIN NUCLEI

\begin{tabular}{lrrrrl}
\hline Brain region & \multicolumn{2}{l}{ Binding (fmol/mg protein) } & \multirow{2}{*}{$\%$ Displacement } \\
\cline { 2 - 5 } & \multicolumn{1}{c}{ Total } & Non-specific & Specific & \\
\hline Ventral hippocampus & $308 \pm 28$ & $130 \pm 7$ & 178 & 57 \\
CA3 & $263 \pm 16$ & $109 \pm 6$ & 152 & 58 \\
Gyrus dentatus & $291 \pm 7$ & $208 \pm 9$ & 83 & 28 \\
Dorsal subiculum & $187 \pm 12$ & $109 \pm 9$ & 78 & 41 \\
Hippocampus molecular layer & $194 \pm 9$ & $118 \pm 7$ & 76 & 39 \\
CA1, CA2 & $208 \pm 9$ & $144 \pm 12$ & 64 & 30 \\
Lateral septum & $248 \pm 7$ & $144 \pm 12$ & 104 & 42 \\
Medial septum & $196 \pm 16$ & $154 \pm 9$ & 42 & 21 \\
Central amygdala & $251 \pm 19$ & $173 \pm 19$ & 78 & 32 \\
Olfactory nucleus & $331 \pm 4$ & $177 \pm 19$ & 154 & 46 \\
Nucleus accumbens & $210 \pm 9$ & $149 \pm 9$ & 61 & 33 \\
Nucleus caudatus & $165 \pm 21$ & 165 & - & - \\
Parietal cortex & $166 \pm 9$ & $113 \pm 14$ & 54 & 38 \\
Entorhinal cortex & $229 \pm 23$ & $142 \pm 9$ & 87 & 38 \\
Substantia nigra & $168 \pm 4$ & $85 \pm 9$ & 83 & 49 \\
Medial geniculate nucleus & $170 \pm 5$ & $99 \pm 14$ & 71 & 41 \\
Dorsal raphe nucleus & $90 \pm 26$ & 52 & 38 & 42 \\
Medial raphe nucleus & 75 & 85 & - & - \\
Nucleus tractus solitarii A & $827 \pm 12$ & $87 \pm 26$ & 140 & 61 \\
Nucleus reticularis & 45 & $66 \pm 7$ & 21 & 22 \\
Medulla oblongata pars ventralis & $135 \pm 11$ & $78 \pm 14$ & 57 & 42 \\
\hline
\end{tabular}

The study was supported by the 'Stichting Pharmacologisch Studiefonds', Utrecht, The Netherlands. We thank Dr. J.P.H. Burbach for analyzing the composition of $\left[{ }^{3} \mathrm{H}\right] \mathrm{AVP}$ samples by HPLC. We gratefully acknowledge the supply of the two AVP antagonists by Dr. Maurice Manning (Department of Biochemistry, Medical College of Ohio, Toledo, OH, U.S.A.). We are grateful to Mr. J.W. Bressers (Organon International B.V., Oss, The Netherlands) for preparation of the photographs. We thank Dr. D. de Wied for critically reading the manuscript.

Fig. 1. Distribution of binding sites for $\left[{ }^{3} \mathrm{H}\right] \mathrm{AVP}$ in the rat brain. A: at the septal level $\mathbf{A}=8000 \mu \mathrm{m}$ (König and Klippel), showing labeling of the lateral septum. B: at the hippocampal level $A=2800 \mu \mathrm{m}$, showing labeling of the dentate gyrus, ventral hippocampus, CA3, medial geniculate nucleus. C: at the hippocampal level $A=1600 \mu \mathrm{m}$ showing labeling of the ventral hippocampus and dentate gyrus. 
1 Bankowski, K., Manning, M., Haldar, J. and Sawyer, W.H., Design of potent antagonists of the vasopressor response to arginine vasopressin, J. med. Chem., 21 (1978) 850-853.

2 Baskin, D.G., Petracca, F. and Dorsa, D.M., Autoradiographic localization of specific binding sites for ${ }^{3} \mathrm{H}$-arginine vasopressin in the septum of the rat brain with tritium sensitive film, Europ. J. Pharmacol., 90 (1983) 155-158.

3 Buijs, R.M., Intra- and extrahypothalamic vasopressin and oxytocin pathways in the rat: pathways to the limbic system, medulla oblongata and spinal cord, Cell Tiss. Res., 192 (1978) 432-435.

4 De Wied, D., Behavioural actions of neurohypophyseal peptides, Proc. Roy. Soc. B., 210 (1980) 183-194.

5 Joëls, M. and Urban, I.J.A., The effect of microiontophoretically applied vasopressin and oxytocin on single neurones in the septum and dorsal hippocampus of the rat, Neurosci. Lett., 33 (1982) 79-84.

$6 \mathrm{Koob}$, G.F. and Bloom, F.E., Behavioral effects of neuropeptides: endorphins and vasopressin, Ann. Rev. Physiol., 44 (1982) 571-582.

7 Kovács, G.L., Bohus, B., Versteeg, D.H.G., De Kloet, E.R. and De Wied, D., Effect of oxytocin and vasopressin on memory consolidation: sites of action and catecholaminergic correlates after local microinjection into limbic-midbrain structures, Brain Res., 175 (1979) 303-314.

8 Kuhar, M.J., Autoradiographic localization of drugs and neurotransmitter receptors in the brain, Trends NeuroSci., 4 (1982) 60-64.

9 Rainbow, T.C., Bleisch, W.V., Biegon, A. and McEwen, B.S., Quantitative densitometry of neurotransmitter receptors, J. Neurosci. Meth., 5 (1982) 127-138.

10 Van Leeuwen, F.W. and Wolters, P., Light microscopic autoradiographic localization of $\left[{ }^{3} \mathrm{H}\right]$ arginine vasopressin binding sites in the rat brain and kidney, Neurosci. Lett., 41 (1983) 61-66.

11 Versteeg, C.A.M., Bohus, B. and De Jong, W., Attenuation by arginine- and desglycinamide lysinevasopressin of a centrally evoked pressor response, J. Auton. Nerv. Syst., 6 (1982) 253-262.

12 Versteeg, D.H.G., Neurohypophyseal hormones and brain neurochemistry, Pharmacol. Ther., 19 (1983) 297-325.

13 Yamamura, H.I., Gee, K.W., Brinton, R.E., Davis, Th.P., Madley, M. and Wamsley, J.K., Light microscopic autoradiographic visualization of ${ }^{3} \mathrm{H}$-arginine vasopressin binding sites in rat brain, Life Sci., 32 (1983) 1919-1924. 